\title{
Experience of a psychiatric trainee by a general practitioner
}

\author{
Christopher OAtes, General Practitioner, Mayford House Surgery, East Road, \\ Northallerton DL6 1NP
}

When the idea was first proposed to our practice that we should have a doctor from the York Psychiatry Rotation attached to our practice as a trainee we were all enthusiastic. As the start date approached and it became more obvious that $I$, as the trainer without a trainee for the six months in question, would be responsible for him I became a little more apprehensive. What if he wore strange clothes? What if he upset all the patients? What if he exposed all my ignorance on matters psychological? When I first spoke to Simon he mentioned that he had not done any acute proper medicine since house jobs, five years previously; I do not know who was more apprehensive - him or me. In the event, of course, I feel the placement was successful and I hope that Simon came away learning a lot about general practice and a significant amount of psychiatry in a different setting.

I was quite offended to hear that the Royal College of Psychiatrists doubted he would be exposed to enough psychiatric morbidity in general practice as I consider it is a major part of our work-load. He had the usual difficulties similar to those experienced by a GP vocational trainee when first starting in a new practice: the strange computer system, all new staff, a way of working quite different to the hospital system, but, of course, because of his experience in psychiatry he was very skilled in verbal communication and in the consultation. Even when the presenting problem was gynaecological or developmental paediatrics, for example, patients did not seem to mind him consulting one of the partners over how to proceed.

I feel the short attachment has taught him in several areas that will be of benefit in his future psychiatric practice. Most importantly he has been exposed to the full range of psychiatric problems as they present in general practice and their management, including normal responses such as bereavement. He has learnt a little about the pathogenesis and management of common, and a few uncommon, general medical and surgical problems. As psychiatric in-patients undoubtedly suffer from these conditions as much as the general population I hope he will feel more confident in advising them.

Finally, I hope he has gained an insight into the working of a modern, and forever trying to keep up with the changes, general medical NHS practice which may help him when he returns to the ever changing NHS hospital service.

\section{The times}

\section{Compulsory treatment in the community in Scotland: ten questions and answers}

\author{
Derek Chiswick, Consultant Forensic Psychiatrist, Royal Edinburgh Hospital, \\ Edinburgh EH10 5HF
}

A recent report by the Royal College of Psychiatrists (1993) on community supervision orders refers to the use of extended leave in Scotland. The legal basis for this practice is uncertain, and some explanation is required.
1. Is a community treatment (or supervision) order specifically mentioned in the Mental Health (Scotland) Act 1984?

No. 
2. Does the Act allow for detained patients to receive treatment in the community on leave of absence?

Yes, in section 27.

\section{How long for?}

For as long as the patient remains liable to detention under the Act. It is known as extended leave of absence.

\section{How does a patient remain liable to detention under the Act?}

This is described in section 30 . The consultant (responsible medical officer) must renew the detention by examining the patient and completing prescribed Form 4 at intervals of six months, six months, and then annually.

\section{What does Form 4 say about the requirement for treatment?}

Form 4 bears the title, 'Renewal of authority for detention in hospital'. It states unambiguously that the patient requires treatment in a hospital. Indeed, the consultant is required to state why treatment in the community is not appropriate. Its use for a patient on leave of absence is a complete contradiction in terms.

\section{Are patients on leave of absence admitted to hospital overnight so that liability to detention can continue?}

No; Form 4 is simply completed, in spite of its contradiction in terms, and submitted to the Mental Welfare Commission for Scotland. The practice of overnight admission for this purpose has been declared illegal in England.

7. Has there been any reported case of a patient on leave of absence appealing against liability to detention?

Yes, AB and CB v E 1987 Scottish Civil Law Reports 419. But the patient was in fact spending three or four days of each week in hospital. The sheriff (judge) refused the appeal but made some important comments. He said that unless detention for some in-patient treatment was "actually appropriate and actually necessary" at the time of the patient's appeal, he would order the discharge of the patient from liability to detention. It therefore seems almost certain that any such appeal by a patient would succeed.

\section{What then is the difference between leave of absence in Scotland and in England?}

Very little according to the respective Mental Health Acts. Section 27 in Scotland is almost identical to section 17 in England. The difference is that leave of absence in England lapses after six months, while in Scotland it may continue for as long as the patient remains liable to be detained. But as we have seen that difference is more apparent than real because of the requirement to satisfy criteria for liability to detention. The most significant difference is that while extended leave of absence has been declared illegal in England, it has yet to be tested in Scotland.

9. How can lengthy leave of absence be implemented under existing law?

It cannot. Mental health laws in Scotland and in England refer to extending leave of absence but only for up to six months in England, and only for longer in Scotland by creative interpretation of the Act. Parliament may, or may not, have wanted lengthy leave of absence provisions, but it has not included them in the legislation.

\section{Should there be such provision?}

That's another matter.

\section{Reference}

Royal College of Psychiatrists (1993) Community Supervision Orders. London: Royal College of Psychiatrists. 